\title{
60 Years of Publishing Fetal and Neonatal Research
}

The journal Neonatology was founded in 1959 as Biologia Neonatorum (formerly Etudes Neo-Natales) (Fig. 1) under the editorship of Professor Alexandre Minkowski [1] who served in this position until 1985. Thereafter, Professor Jean-Pierre Relier [2] became editor-in-chief of the journal, which was renamed Biology of the Neonate in 1970 (Fig. 2), from 1986 until 2003. In 1993, another Karger journal, Developmental Pharmacology and Therapeutics, under the editorship of Professor Jack Aranda from 1981, was incorporated in Biology of the Neonate. In 2007, Biology of the Neonate was again renamed Neonatology (Fig. 3), and it is with this name that we celebrate 60 years in existence. So, 1959, the year of our birth, was a special year in more than one respect:

- Mercury was identified as the cause of Minamata disease

- Joseph Murray performed the world's first allotransplantation

- The first known case of HIV infection was recognised in the Belgian Congo

- Charles de Gaulle was inaugurated as first President of the French Fifth Republic

- The European Court of Human Rights was established

- Fidel Castro led a revolution in Cuba

- Alaska was admitted as the 49th US state, and President Eisenhower also granted statehood to Hawaii

- Boeing 707 began service

- The Soviet Union launched Luna 1 spacecraft, later followed by Luna 2 which crashed into the moon, and Luna 3 which photographed the far side of the moon

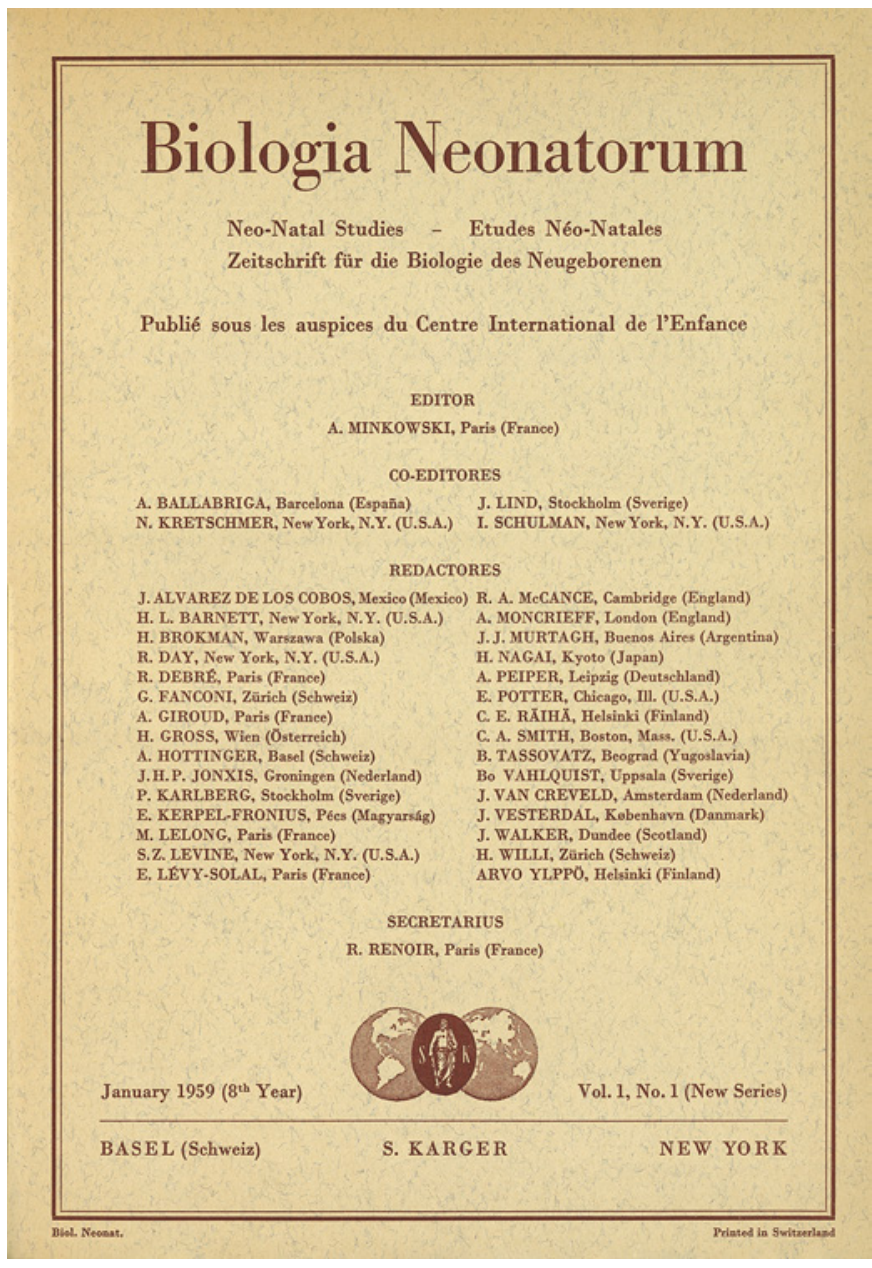

Fig. 1. Cover of the first issue of Biologia Neonatorum, 1959.

\section{KARGER}

(C) 2019 S. Karger AG, Basel 


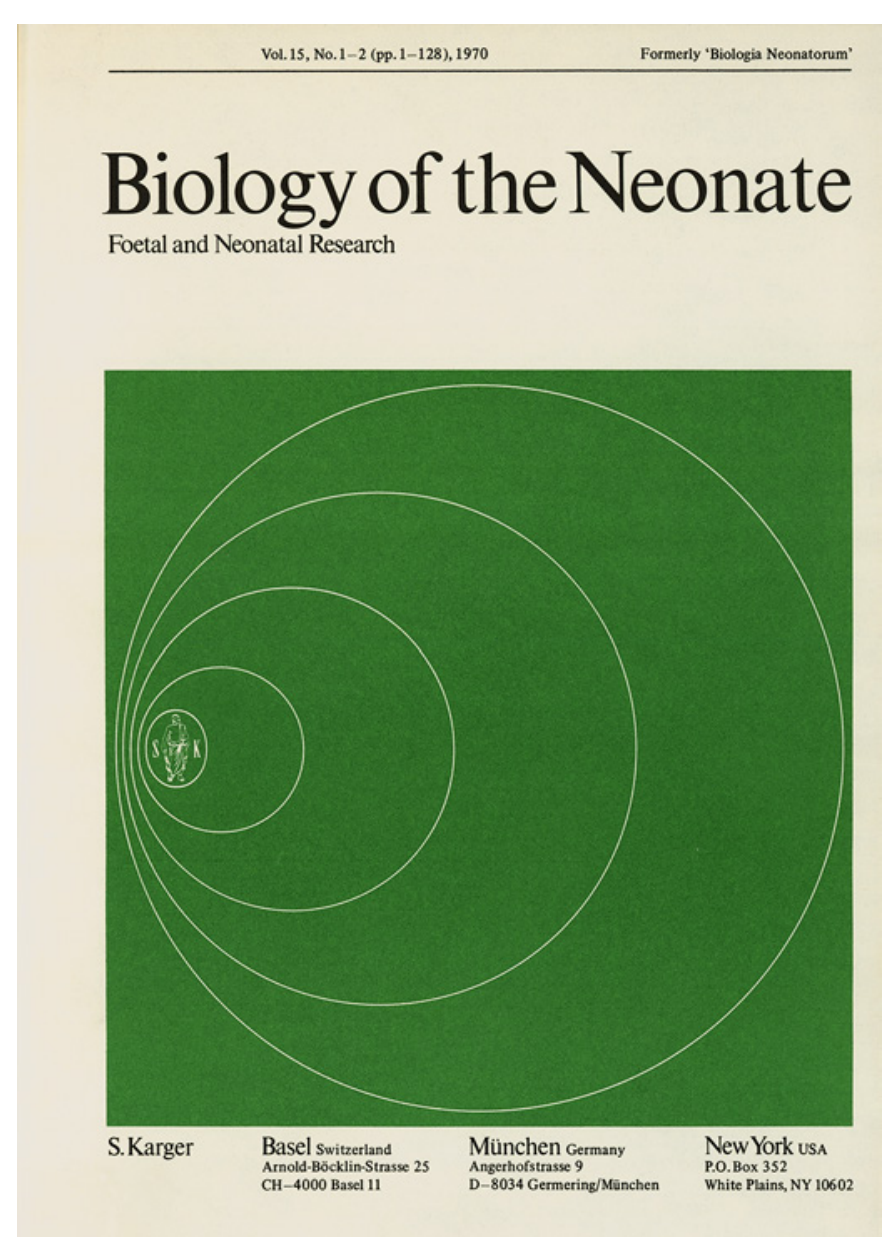

Fig. 2. Cover of the first issue of the renamed journal Biology of the Neonate, 1970.

- In Cape Canaveral Jupiter AM-18 launched 2 monkeys into space

- The Saint Lawrence Seaway was opened by Elizabeth II and President Eisenhower

- The original Mini car was launched at a cost of GBP 500

- Buddy Holly died in an air crash in Iowa

- Cecil B. DeMille, film director, and Errol Flynn, actor, died

- The Marx brothers made their last television appearance

In 1959 the first issue of Biologia Neonatorum (Biology of the Neonate) had a Foreword from Alexandre Minkowski which began: "The most memorable characteristic of the complex sequence of events resulting in the growth, development and birth of the human fetus is the fact that, as a rule, the process unfolds normally and without mis-

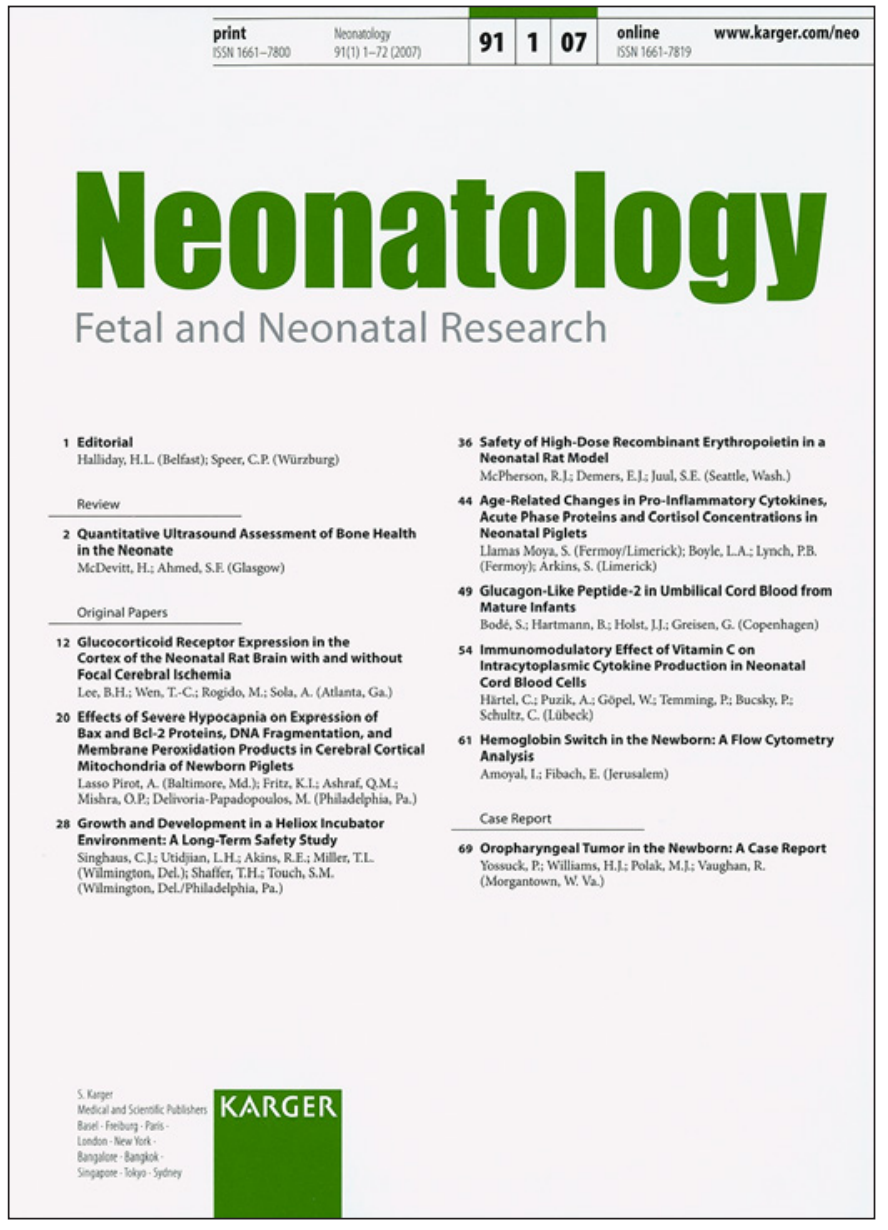

Fig. 3. Cover of the first issue of the renamed journal Neonatology, 2007.

hap" [3]. Thankfully, this still holds true today in 2019. The first issue had only 3 articles - the first was a study of the endocrine glands in anencephalic fetuses [4], another on cleft palate in the offspring of mice treated with ACTH during pregnancy [5], and the third was a paper from J.C. Larroche, the renowned perinatal pathologist from PortRoyal Hospital, Paris, and his colleagues (including Alexandre Minkowski) on the development of pulmonary arteries and arterioles from fetal to neonatal life [6]. Of interest is the easy mixing of French and English titles for these first papers. Indeed, Alexandre Minkowski's Foreword was written in English, French, and German [3]. Today, of course, English is accepted as the language of science and medicine.

From just 3 papers in 1959, Biology of the Neonate (now Neonatology) has developed into a journal reporting about a dozen articles per issue with papers varying 
from systematic reviews with meta-analyses to original articles, short communications, and letters to the editor. Original papers present research on all aspects of neonatology, fetal medicine, and developmental biology. These papers encompass both basic science and clinical research including randomised trials, observational studies, and epidemiology. Basic science research covers molecular biology, molecular genetics, physiology, biochemistry, and pharmacology in fetal and neonatal life. In addition, the journal accepts papers for the sections Research Briefings and Sources of Neonatal Medicine covering historical pieces. Papers reporting the results of animal studies need to be based upon hypotheses that relate to developmental processes or disorders in the human fetus or neonate.

This anniversary gives us the opportunity to express our sincere gratitude to all reviewers who have critically evaluated manuscripts during the past 60 years; moreover, we would like to thank all the authors of excellent articles published in Neonatology. We are also most grate- ful to S. Karger Medical and Scientific Publishers and the responsible team for Neonatology, especially Thomas Nold, for a very constructive and fruitful collaboration during the past 15 years.

We have come a long way since Alexandre Minkowski said in his Foreword 60 years ago - "Two types of papers will be accepted in this journal: on the one hand, papers presenting a survey of ascertained or nearly certain facts in the form of general review articles; on the other hand, papers describing original research, and for these the policy will be that a good idea and satisfactory preliminary report will be acceptable even if no formal conclusion is reached, research consisting often in raising problems before solving them" [3]. However, we, as editors in 2019, agree with the sentiments of the first editor when he said that he hoped that following its birth in 1959 the new journal will live and thrive. Here's to the next 60 years.

Henry L. Halliday, Belfast Christian P. Speer, Würzburg

\section{References}

60 Years of Publishing Fetal and Neonatal Research
1 Relier JP. Obituary: Alexandre Minkowski 1915-2004. Biol Neonate. 2004;86:183.

2 Halliday HL, Speer CP. Professor Jean-Pierre Relier. Neonatology. 2018;114(3):251-2.

3 Minkowski A. Foreword - Avant-propos Vorwort. Biol Neonate. 1959;1(1):1-7.

4 Tuchmann-Duplessis H. Etude des glandes endocrines des anencephales. Biol Neonate. $1959 ; 1(1): 8-32$
5 Heiberg K, Kalter H, Fraser FC. Production of cleft palates in the offspring of mice treated with ACTH during pregnancy. Biol Neonat. 1959 Jan; 1(1):33-7.

6 Larroche JC, Nodot A, Minkowski A, Fleurquin N. Developpement des arteries et arterioles pulmonaires de la periode faetale a la periode neonatale. Biol Neonate. 1959;1(1): $37-60$. 